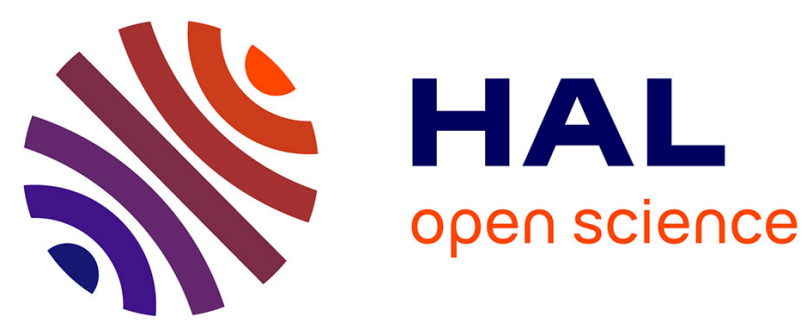

\title{
CATIONIC DISTRIBUTION IN BaFe12-2xCoxSnxO19 HEXAGONAL FERRITES SUITABLE FOR MAGNETIC RECORDING
}

\author{
X. Batlle, J. Rodriguez, X. Obradors, M. Pernet, Maxime Vallet, J. \\ Fontcuberta
}

\section{To cite this version:}

X. Batlle, J. Rodriguez, X. Obradors, M. Pernet, Maxime Vallet, et al.. CATIONIC DISTRIBUTION IN BaFe12-2xCoxSnxO19 HEXAGONAL FERRITES SUITABLE FOR MAGNETIC RECORDING. Journal de Physique Colloques, 1988, 49 (C8), pp.C8-939-C8-940. 10.1051/jphyscol:19888428 . jpa00228624

\section{HAL Id: jpa-00228624 https://hal.science/jpa-00228624}

Submitted on 1 Jan 1988

HAL is a multi-disciplinary open access archive for the deposit and dissemination of scientific research documents, whether they are published or not. The documents may come from teaching and research institutions in France or abroad, or from public or private research centers.
L'archive ouverte pluridisciplinaire HAL, est destinée au dépôt et à la diffusion de documents scientifiques de niveau recherche, publiés ou non, émanant des établissements d'enseignement et de recherche français ou étrangers, des laboratoires publics ou privés. 


\title{
CATIONIC DISTRIBUTION IN BaFe 12 $2 x \mathrm{Co}_{x} \mathrm{Sn}_{x} \mathrm{O}_{19}$ HEXAGONAL FERRITES SUITABLE FOR MAGNETIC RECORDING
}

\author{
X. Batlle, J. Rodriguez ${ }^{1}$, X. Obradors, M. Pernet ${ }^{2}$, M. Vallet ${ }^{3}$ and J. Fontcuberta \\ Fac. Fisica. Universitat de Barcelona, Diagonal 647. 08028 Barcelona, Spain
}

\begin{abstract}
The cation distribution in the $\mathrm{BaFe}_{12-2 x} \mathrm{Co}_{x} \mathrm{Sn}_{x} \mathrm{O}_{19}$ compounds has been investigated by means of powder neutron diffraction. The atomic occupancies of the $2 \mathrm{a}, 4 \mathrm{e}$ and $4 \mathrm{f}_{\mathrm{iv}}$ are unambigously determined while the atomic contents of the $12 \mathrm{k}$ and $4 \mathrm{f}_{\mathrm{vi}}$ octahedral positions are strongly delimited. A considerable amount of Co ions occupy the tetrahedral positions thus reducing the effect of these ions as a source of the decrease of the uniaxial anisotropy.
\end{abstract}

Recent reports on the synthesis and characterization of hexagonal ferrite particles [1-3] have shown that the liquid mix technique may be a valuable method to obtain single domain particles for perpendicular magnetic recording. In order to get particles suitable for magnetic recording it is well known that some $\mathrm{Co}^{2+}$ doping is necessary to reduce the intrinsically high uniaxial magnetic anisotropy of $\mathrm{BaFe}_{12} \mathrm{O}_{19}$ [4]. In a recent work [3] we have proved that $\mathrm{Co}^{2+}+\mathrm{Sn}^{4+}$ doping may constitute an interesting alternative to the usual $\mathrm{Co}^{2+}+\mathrm{Ti}^{4+}$ doping scheme because similar decreases of the coercitive field may be obtained with a lower substitution rate. We have now investigated by means of powder neutron diffraction and Mössbauer spectroscopy the cation distribution in the $\mathrm{BaFe}_{12-2 x} \mathrm{Co}_{x} \mathrm{Sn}_{x} \mathrm{O}_{19}$ hexagonal ferrites. A study of the isomorphous $\mathrm{Ti}$ compounds is in progress for comparison pourpose.

The synthesis of the $\mathrm{BaFe}_{12-2 x} \mathrm{Co}_{x} \mathrm{Sn}_{x} \mathrm{O}_{19}(0 \leq x \leq$ 1.0) samples used in this investigation was performed by the liquid mix technique as it was described in a previous work [3].

Powder neutron diffraction patterns were recorded at the D2B of the I.L.L. using $\lambda=1.594 \AA$. All spectra were obtained at $T=520^{\circ} \mathrm{C}$ in the paramagnetic phase and the diffracton paterns were refined by the Rietveld method [5]. The positional parameters together with occupation factors $P_{i}$ corresponding to the five sublattices of the M-structure were simultaneously refined.

Details of the refinement procedure will be published elsewhere. Immediately after the first runs it was evident that no Co or Sn substitution takes place in the octahedral $2 \mathrm{a}$ and pseudotetrahedral $4 \mathrm{e}$ sublattices up to $x=1.0$, while some substitution occurs in the remaining $4 f_{i v}, 4 f_{v i}$ and $12 \mathrm{k}$ sublattices. Figure 1 shows the composition dependence of the refined occupation factors assuming $b=b(\mathrm{Fe})$ for these positions. The

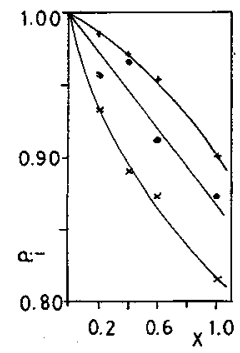

Fig. 1. - Refined occupation factors $P_{i}$ of the different sublattices refered to full Fe occupancy $\left((x): 4 f_{\mathrm{iv}} ;(\bullet): 4 f_{\mathrm{vi}}\right.$; $(+): 12 \mathrm{~K}$ ).

observed decrease of these $P_{i}$ values is indicative of the substitution with Co or $\mathrm{Sn}$ ions which have lower scattering lenghts. When these occupation factors are converted to atomic occupancies a system of four equations having six variables can be constructed. To solve this system some physical hypothesis are in order. The first hypothesis we have considered is that $\mathrm{Sn}$ atoms are not located on the tetrahedral $4 f_{\text {iv }}$ sublattice. In this way the occupancy rate of Co ions in the tetrahedral site may be immediately found. See figure 2 . Because a small amount of the $\mathrm{CoFe}_{2} \mathrm{O}_{4}$ and $\alpha-\mathrm{Fe}_{2} \mathrm{O}_{3}$ oxides were observed as impurities we have not imposed the total Co contents in the M-phase. Instead the Sn contents, was restricted to the nominal values. In this way, we have computed the occupation ratio assuming two limiting situations: i) no $\mathrm{Sn}$ atoms are located in the $4 f_{\text {vi }}$ sublattice, ii) no $S n$ atoms are located in the $12 \mathrm{k}$ sublattice. The results obtained within the first hypothesis are displayed in figure $2 a$ while the second limit led to anomalous Co occupancy in the $4 \mathrm{f}_{\mathrm{vi}}$ sublattice where a change in the slope of the occupation ratio as a function of $x$ was found.

In order to get a physical result where the $\mathrm{Co}\left(4 \mathrm{f}_{\mathrm{vi}}\right)$ occupancy steadily increases with $x$, we computed the occupancy ratio for several $\mathrm{Sn}$ distributions among the

\footnotetext{
${ }^{1}$ I.L.L., 156X, 38042 Grenoble, France.

${ }^{2}$ Lab. Cristallographie, CNRS $166 \mathrm{X}$, Grenoble, France.

${ }^{3}$ Fac. Quimica. Universidad Complutense, 28040 Madrid, Spain.
} 


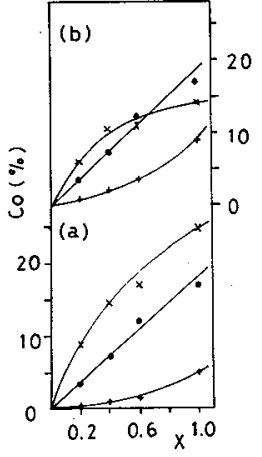

Fig. 2. - Co substitution percentage in the different sublattices refered to the total occupancy of each position $((x)$ : $4 f_{\mathrm{vi}} ;(0): 4 \mathrm{f}_{\mathrm{iv}} ;(+): 12 \mathrm{~K}$ ) assuming that: (a) no $\mathrm{Sn}$ atoms are located in the $4 f_{\mathrm{vi}}$ sublattice, and (b), the $\mathrm{Sn}$ occupancy ratio between $12 \mathrm{k}$ and $4 f_{\mathrm{vi}}$ sublattices is 1.2 .

$12 \mathrm{k}$ and $4 \mathrm{f}_{\mathrm{vi}}$ sublattices. We found that the Sn occupation ratio between $12 \mathrm{k}$ and $4 \mathrm{f}_{\mathrm{vi}}$ positions must be at least 1.2. The cation distribution resulting from this limit is represented in figure $2 b$.

We should remark that although the atomic contents of the $4 f_{v i}$ and $12 \mathrm{k}$ positions may not be completely determined our results allow us to define two strongly stringent limits, as reported in figures $2 a$ and $2 b$.

It is worth to emphasize that the composition dependence of the mean interatomic distances in these positions are consistent with the ionic radius of the $\mathrm{Fe}^{3+}, \mathrm{Co}^{2+}$ and $\mathrm{Sn}^{4+}$ contents in all the positions.

Finally, we note that in principle the ambiguity remaining in the neutron diffraction analysis could be lifted by using Mössbauer spectroscopy. However, because of strong perturbation of the magnetic spectra induced by the existence of atomic disorder the fitted intensities own an important uncertainty which precluded any further precission in our results.

Summarizing our neutron diffraction study of the $\mathrm{BaFe}_{12-2 x} \mathrm{Co}_{x} \mathrm{Sn}_{x} \mathrm{O}_{19}$ series has allowed to ascertain that two sublattice are fully occupied by Fe ions ( $2 \mathrm{a}$ and $4 \mathrm{e}$ ) and that the tetrahedral $4 \mathrm{f}_{\mathrm{iv}}$ sublattice is occupied by a non negligible amount of $\mathrm{Co}^{2+}$ ions. For the $12 \mathrm{k}$ and $4 \mathrm{f}_{\mathrm{vi}}$ sites we have stablished a narrow interval of possible compositions. This last uncertainity could be probably raised performing saturation magnetization measurements at low temperatures. This study is presently underway.

We would like finally to stress the relevance of our results concerning the macroscopic magnetic properties of the Co-substituted M-type hexagonal ferrites. The most important point is that a considerable amount of $\mathrm{Co}^{2+}$ ions occupy the tetrahedral $4 \mathrm{f}_{\mathrm{iv}}$ position thus being ineffective in the reduction the uniaxial magnetic anisotropy. This is also probably the clue for the understanding of the different magnetic behaviour of the $\mathrm{Ti}$ and $\mathrm{Sn}$ substituted M-type hexagonal ferrites.

\section{Acknowledgements}

We are greatful to Professor J. Tejada for his contribution to the magnetic measurements. The financial support of CAICYT project $n^{\circ} 916 / 84$ is also recognized.

[1] Vallet, M., Rodriguez, P., Obradors, X., Isalgué, A., Rodriguez, J., Pernet, M., J. Phys. Colloq. France 46 (1985) C6-335.

[2] Ardiaca, R., Ramos, R., Isalgué, A., Rodriguez, J., Obradors, X., Pernet, M., Vallet, M., IEEE Trans. Magn. MAG 23 (1987) 22.

[3] Pernet, M., Obradors, X., Vallet, M., Hernádez, T., Germi, P., IEEE Trans. Magn. (in press).

[4] Kubo, O., Ido, T., Yokozama, M., IEEE Trans. Magn. 18 (1982) 1122.

[5] Rodriguez, J., Pannetier, J., Anne, M., STRAP.

[6] Collomb, A., Wolfers, P., Obradors, X., J. Magn. Magn. Mater. 62 (1986) 57. 